\title{
DEPTH-3 AdJACENCY Cluster BASED Routing PROTOCOL
}

\author{
Prasad Patil \& Rinku Shah \\ Department of Computer Engineering, Mumbai University, Mumbai ,India
}

\begin{abstract}
In general, existing routing protocols in adhoc networks can be classified as proactive, reactive or hybrid. Proactive protocols are table driven. Proactive protocols maintain entire topology of network. So whenever there is routing request connection is established quickly. Reactive protocols are also known as On-demand protocols. On demand protocols based on fact that there is no point in maintaining network topology since it is always changing. Hybrid protocols combines approach of both reactive and proactive. Cluster based routing protocol (CBRP) is hybrid routing protocol designed for MANET. By clustering nodes into groups, the protocol efficiently minimizes flooding, traffic during route discovery. However we have realized mobility of the nodes is not considered in route reply process of the protocol. There is no mechanism defined for mobility of cluster head in route reply process. In this paper we have studied existing routing strategies in MANET and proposed a solution to the drawback we found in CBRP. Performance of CBRP will enhanced using our proposed solution.
\end{abstract}

\section{KEYWORDS}

MANET; Hybrid routing; CBRP

\section{INTRODUCTION}

In next generation of wireless communication systems, there is a tremendous need for the rapid deployment of independent mobile users. Significant examples include emergency search/rescue missions, disaster relief efforts, mine site operations, battlefield military operations, electronic classrooms, conferences, convention centers, [1] etc. A network of such users is referred to as Mobile Ad hoc Network (MANET). Such a network does not have any fixed infrastructure (i.e., no base stations/ routers); nodes arbitrarily change their positions resulting in a highly dynamic topology causing wireless links to be broken and re-established on the- fly. In MANET world devices such as laptops, PC, pda etc with adhoc communication link capability. MANET is infrastructure less multihop network

Routing in ad hoc networks has been an active research area and in recent years numerous routing protocols have been introduced for MANETs. The deployment of such networks still faces challenges, such as limited physical security, node mobility, and limited resources[2,3] (i.e., processor, power, bandwidth, storage). The major issues that affect the design, deployment, and performance of a MANET include: medium access scheme, routing, multicasting, transport layer protocol, pricing scheme, quality of service provisioning, self organization, security, energy management, addressing and service discovery, scalability and deployment consideration. The protocol design issues are inherently related to the underlying ad hoc applications. Routing protocols are designed for purposes such as quality of service provisioning, energy management and security.

Section 2 describes different constraints on routing in MANET. Adhoc network has different constraints on routing than any other network.

Section 3 has a overview of current routing strategies. Present routing strategies viz. proactive, reactive and hybrid are discussed. 
In section 4 we have discussed design flaw that we have found in CBRP. Also proposed a solution for it . Finally we have drawn conclusion in Section 5.

\section{Constraint on Routing in Manet}

Major challenges that a routing protocol designed for Ad Hoc wireless networks faces include: mobility of nodes, resource constraints, error-prone channel state, and hidden and exposed terminal problems.

Mobility: the network topology in an ad hoc wireless network is highly dynamic due to the movement of nodes and the addition of new nodes to the network. Disruption in service may occur either due to the movement of the intermediate nodes in the path or due to the movement of the end nodes.

Bandwidth constraints: in wireless networks, the capacity of the radio band is limited and hence the data rates it can offer are much less than what a wired network can offer. That is why the routing protocol should use the bandwidth optimally to keep the overhead as low as possible.

Error-Prone Channel state: the wireless links have time-varying characteristics in terms of link capacity and link-error probability. This requires that the ad hoc wireless network routing protocol should interact with the MAC layer to find alternate routes through better quality links.

Hidden terminal problem: refers to the collision of packets at a receiving node due to the simultaneous transmission of those nodes that are not within the direct transmission range of the sender, but are within the transmission range of the receiver. Collations occur when both nodes transmit packets at the same time without knowing about the transmission of each other. Solution to this problem includes the use of Medium Access Collision Avoidance for Wireless MACAW. This protocol requires that the receiver acknowledges each successful reception of data packet. Successful transmission is a four-way exchange mechanism, namely RTS-CTS-Data-ACK.

Exposed terminal problem: refers to the inability of a node to transmit to another node when the wireless channel is not free due to transmission by the nearby transmitting node.

Resource constraints: battery life and processing power are two essential and limited resources that form the major constraint for the nodes in an ad hoc network. Thus ad hoc wireless network routing protocols must optimally manage these resources.

\section{Existing Routing STRATEgies}

There, are three types of flat routing strategies exist in MANET. These are reactive, proactive and hybrid [4].

\subsection{Proactive Routing}

Proactive MANET protocols are also called as table-driven protocols and will actively determine the layout of the network. Through a regular exchange of network topology packets between the nodes of the network, at every single node an absolute picture of the network is maintained. There is hence minimal delay in determining the route to be taken. This is especially important for time-critical traffic. When the routing information becomes worthless quickly, there are many short-lived routes that are being determined and not used before they turn invalid. Therefore, another drawback resulting from the increased mobility is the amount of traffic overhead generated when evaluating these unnecessary routes. This is especially altered when the network size increases. The portion of the total control traffic that consists of actual practical data is further decreased. Lastly, if the nodes transmit infrequently, most of the routing information is considered redundant. The nodes, however, continue to expend energy by continually updating these unused entries in their routing tables as mentioned, energy conservation is very important in a MANET system design. Therefore, this excessive expenditure of energy is not desired. Thus, proactive MANET protocols work best in networks that have low node mobility or where the nodes transmit data frequently. Examples of proactive routing protocols are optimized link state routing protocol (OLSR)[5], destination sequenced distance vector routing (DSDV)[6].

\subsection{Reactive routing}


Portable nodes- Notebooks, palmtops or even mobile phones usually compose wireless ad-hoc networks. This portability also brings a significant issue of mobility. This is a key issue in ad-hoc networks. The mobility of the nodes causes the topology of the network to change constantly. Keeping track of this topology is not an easy task, and too many resources may be consumed in signalling. Reactive routing protocols were intended for these types of environments. These are based on the design that there is no point on trying to have an image of the entire network topology, since it will be constantly changing. Instead, whenever a node needs a route to a given target, it initiates a route discovery process on the fly, for discovering out a pathway.

Reactive protocols start to set up routes on-demand. The routing protocol will try to establish such a route, whenever any node wants to initiate communication with another node to which it has no route. This kind of protocols is usually based on flooding the network with Route Request (RREQ) and Route reply (RERP) messages .By the help of Route request message the route is discovered from source to target node; and as the target node gets a RREQ message it send RERP message for the confirmation that the route has been established. This kind of protocol is usually very effective on single-rate networks. It usually minimizes the number of hops of the selected path. However, on multi-rate networks, the number of hops is not as important as the throughput that can be obtained on a given path. Examples of reactive routing protocols are adhoc on demand distance vector (AODV)[8], Dynamic source routing(DSR)[7].

\subsection{Hybrid Routing}

Since proactive and reactive protocols each work best in oppositely different scenarios, hybrid method uses both. It is used to find a balance between both protocols. Proactive operations are restricted to small domain, whereas, reactive protocols are used for locating nodes outside those domains.

Both methods explained before, only demonstrate good performance under certain conditions. But what if a balance point between proactive and reactive routing is found by adjusting the degree to which route information is propagated proactively versus the degree to which it needs to be discovered reactively? If we combine the advantages of both techniques obtaining as a result a particular routing protocol which is able to adapt himself to the behavior of the network.

By a Hybrid routing protocol the following characteristics must be present

- Adaptive: should be applicable to wide range of network characteristics. Node mobility, traffic patterns should be handled easily.

- Flexible: should enable the optimization. Applications should be able to be adapted to the different application-specific metrics at the routing layer. These goals should be set by the network participants

- Efficient and Practical: The protocol should achieve better performance than pure, non-hybrid, strategies without invoking costly low-level primitives. Such as reliable broadcasts and distributed agreements

Hybrid protocols try to explode the benefits of both Proactive and Reactive protocols.

- The proactive part of the protocol is reduced to a small neighborhood of a node. The network is divided in small networks in order to decrease the problem of delay.

- The reactive part is used for routing across the network. Routing in large scale networks is implemented to reduce the overhead control problem.

The main difference between the Hybrid Adaptive protocols is the way they implement the PRP and RRP, and the way they define the routing zones. Next, we will briefly describe the most known Hybrid protocol, to finally compare them with each other

Example of hybrid protocols are zone routing protocol (ZRP)[9], cluster based routing protocol(CBRP)[10].

Table 1. Comparison of current protocols

\begin{tabular}{|l|l|l|l|l|l|l|}
\hline Parameter & AODV & DSR & DSDV & OLSR & ZRP & CBRP \\
\hline $\begin{array}{l}\text { Control } \\
\text { message }\end{array}$ & $\begin{array}{l}3 \text { types- } \\
\text { RREQ,RREP,RERR }\end{array}$ & $\begin{array}{l}3 \text { types- } \\
\text { RREQ,RREP,RERR }\end{array}$ & $\begin{array}{l}2 \text { type- } \\
\text { HELLO \& } \\
\text { Update }\end{array}$ & $\begin{array}{l}\text { 2 type- } \\
\text { HELLO and } \\
\text { TC }\end{array}$ & $\begin{array}{l}\text { Hello, } \\
\text { Update, for } \\
\text { inter zone- } \\
\text { RREQ,RREP }\end{array}$ & $\begin{array}{l}\text { HELLO } \\
\text {,RREQ,RREP,RERR }\end{array}$ \\
\hline $\begin{array}{l}\text { Central } \\
\text { Administration }\end{array}$ & NO & NO & NO & NO & node & Cluster head \\
\hline Route discover & Each source node & Each source node & Already have & Already have & For intra zone & For intra cluster have \\
\hline
\end{tabular}


International Journal of Engineering Sciences \& Emerging Technologies, Feb 2012. ISSN: 2231 - 6604 doi: 10.7323/ijeset/v1_i2_9 Volume 1, Issue 2, pp: 77-82 OIJESET

\begin{tabular}{|c|c|c|c|c|c|c|}
\hline & $\begin{array}{l}\text { broadcast RREQ on } \\
\text { demand }\end{array}$ & $\begin{array}{l}\text { broadcast RREQ on } \\
\text { demand }\end{array}$ & $\begin{array}{l}\text { info for all } \\
\text { destination }\end{array}$ & $\begin{array}{l}\text { info for all } \\
\text { destination }\end{array}$ & $\begin{array}{l}\text { have info, } \\
\text { but for inter } \\
\text { zone } \\
\text { broadcast } \\
\text { RREQ }\end{array}$ & $\begin{array}{l}\text { info, but for inter } \\
\text { zone broadcast } \\
\text { RREQ }\end{array}$ \\
\hline $\begin{array}{l}\text { Loop free } \\
\text { routing }\end{array}$ & $\begin{array}{l}\text { Yes, Due to } \\
\text { sequence no. }\end{array}$ & $\begin{array}{l}\text { Yes, due to address } \\
\text { in packet header }\end{array}$ & $\begin{array}{l}\text { Yes, due to } \\
\text { sequence no. }\end{array}$ & $\begin{array}{l}\text { Yes, due to } \\
\text { sequence no. }\end{array}$ & $\begin{array}{l}\text { Yes, due to } \\
\text { sequence no. }\end{array}$ & $\begin{array}{l}\text { Yes, due to sequence } \\
\text { no. }\end{array}$ \\
\hline $\begin{array}{l}\text { Type of } \\
\text { routing }\end{array}$ & Hop by hop & Source routing & Hop by hop & Hop by hop & $\begin{array}{l}\text { Hop by hop } \\
\text { and source }\end{array}$ & Source routing \\
\hline Link support & Symmetric & Symmetric & Symmetric & $\begin{array}{l}\text { Link to } \\
\text { MPR- } \\
\text { Symmetric, } \\
\text { rest can be } \\
\text { anything }\end{array}$ & Symmetric & $\begin{array}{l}\text { Symmetric, } \\
\text { Selective } \\
\text { Asymmetric }\end{array}$ \\
\hline $\begin{array}{l}\text { How path is } \\
\text { build }\end{array}$ & $\begin{array}{l}\text { By keeping } \\
\text { backward pointer } \\
\text { and forwards RREQ }\end{array}$ & $\begin{array}{l}\text { Intermediate node } \\
\text { insert its address in } \\
\text { packer }\end{array}$ & $\begin{array}{l}\text { Next hop is } \\
\text { calculated by } \\
\text { neighbours } \\
\text { routing table }\end{array}$ & $\begin{array}{l}\text { Next hop is } \\
\text { calculated by } \\
\text { neighbours } \\
\text { routing table }\end{array}$ & $\begin{array}{l}\text { Intra zone by } \\
\text { routing table, } \\
\text { inter zone on } \\
\text { demand }\end{array}$ & $\begin{array}{l}\text { Intra cluster by } \\
\text { routing table, inter } \\
\text { cluster on demand }\end{array}$ \\
\hline Scalable & $\begin{array}{l}\text { Yes but vulnerable } \\
\text { to network change }\end{array}$ & No & No & No & Yes & No \\
\hline Protocol type & Reactive & Reactive & Proactive & Proactive & Hybrid & Hybrid \\
\hline Metric & Shortest path & Shortest path & Shortest path & Cost & Shortest path & Shortest path \\
\hline Advantage & $\begin{array}{l}\text { At higher load incur } \\
\text { lower delay; } \\
\text { Unicast, multicast } \\
\text { and broadcast } \\
\text { communication } \\
\text { possible. }\end{array}$ & $\begin{array}{l}\text { Better in terms of } \\
\text { collision; } \\
\text { Doesn't flood } \\
\text { network with } \\
\text { updates; } \\
\text { Routes maintained } \\
\text { only when } \\
\text { communication is } \\
\text { done; } \\
\text { Single route } \\
\text { discovery may } \\
\text { result multiple route } \\
\text { to same destination }\end{array}$ & $\begin{array}{l}\text { In small } \\
\text { network size } \\
\text { delay is } \\
\text { smallest and } \\
\text { throughput is } \\
\text { high; } \\
\text { Guarantees } \\
\text { loop free }\end{array}$ & $\begin{array}{l}\text { Limited } \\
\text { broadcasting } \\
\text { due to MPR; } \\
\text { Being } \\
\text { proactive } \\
\text { routes to all } \\
\text { destination } \\
\text { available; } \\
\text { Useful in } \\
\text { application } \\
\text { where less } \\
\text { route } \\
\text { discovery } \\
\text { delay } \\
\text { required }\end{array}$ & $\begin{array}{l}\text { It tries to } \\
\text { maintain most } \\
\text { up to date } \\
\text { map of } \\
\text { network; } \\
\text { Requires less } \\
\text { bandwidth ; } \\
\text { Mobility of } \\
\text { cluster head }\end{array}$ & $\begin{array}{l}\text { Use of clustering to } \\
\text { minimize on demand } \\
\text { route discovery; } \\
\text { Link broken locally } \\
\text { repaired; }\end{array}$ \\
\hline Disadvantage & $\begin{array}{l}\text { Collision is high; } \\
\text { Route discovery } \\
\text { latency in high scale } \\
\text { network; } \\
\text { Lack of efficient } \\
\text { maintenance } \\
\text { technique }\end{array}$ & $\begin{array}{l}\text { Access delay } \\
\text { increases and } \\
\text { throughput decrease } \\
\text { as increase in } \\
\text { network size; } \\
\text { Route maintenance } \\
\text { mechanism doesn't } \\
\text { locally repair } \\
\text { broken link ; } \\
\text { Route cache may } \\
\text { stale; } \\
\text { Connection set up } \\
\text { delay is high; } \\
\text { As network grows } \\
\text { packet header size } \\
\text { grows }\end{array}$ & $\begin{array}{l}\text { Higher delays } \\
\text { for large } \\
\text { network; } \\
\text { Wastage of } \\
\text { bandwidth } \\
\text { due to } \\
\text { unnecessary } \\
\text { updates even } \\
\text { if no change; } \\
\text { Difficult to } \\
\text { determine } \\
\text { time delay for } \\
\text { advertisement }\end{array}$ & $\begin{array}{l}\text { Due to } \\
\text { periodic } \\
\text { update } \\
\text { bandwidth is } \\
\text { wasted; } \\
\text { Maintains } \\
\text { route most } \\
\text { of which } \\
\text { never used }\end{array}$ & $\begin{array}{l}\text { Latency for } \\
\text { finding new } \\
\text { routes; } \\
\text { If node not in } \\
\text { any zone } \\
\text { cannot } \\
\text { communicate }\end{array}$ & $\begin{array}{l}\text { Due to source } \\
\text { routing, if network } \\
\text { size grows packet } \\
\text { size increases; } \\
\text { Useful in small } \\
\text { cluster only }\end{array}$ \\
\hline
\end{tabular}

\section{Cluster Based Routing Protocol}

Cluster Based Routing Protocol (CBRP) is a routing protocol designed for use in mobile ad hoc networks. The protocol divides the nodes of the ad hoc network into a number of overlapping or disjoint 1-hop- radius clusters in a distributed manner. A cluster head is elected for each cluster to maintain cluster membership information. Inter- cluster routes are discovered dynamically using the cluster membership information kept at each cluster head. By clustering nodes into groups, the protocol efficiently minimizes the flooding traffic during route discovery and speeds up this process as well. Furthermore, the protocol takes into consideration the existence of uni-directional links and uses these links for both intra-cluster and inter cluster routing

\subsection{Design Flaw}

Clusters are identified by its head address. In Route Discovery, only cluster heads are flooded with Route Request Packets (RREQ). To perform Route Discovery to D, the source node S sends out an 
RREQ, with the target node address field set to D. Intermediate cluster heads forwards RREQ packet to their neighbouring clusters. Each intermediate cluster head and gateway attach its own address in RREQ packet. Upon receiving this packet by the target node, it constructs route reply packet. RREP packet constructed on basis of intermediate cluster addresses. Suppose intermediate cluster head moves, new clusters may form. So according to defined method, when RREP packet on its way ,it is discarded by pre intermediate node of new clusters. This packet would not recognize this new clusters. There is no mechanism defined for this scenario. And finally when timer expires this whole procedure is repeated again. So mobility of nodes is not considered in RREP process. This is major issue even if one intermediate cluster head moves on path.

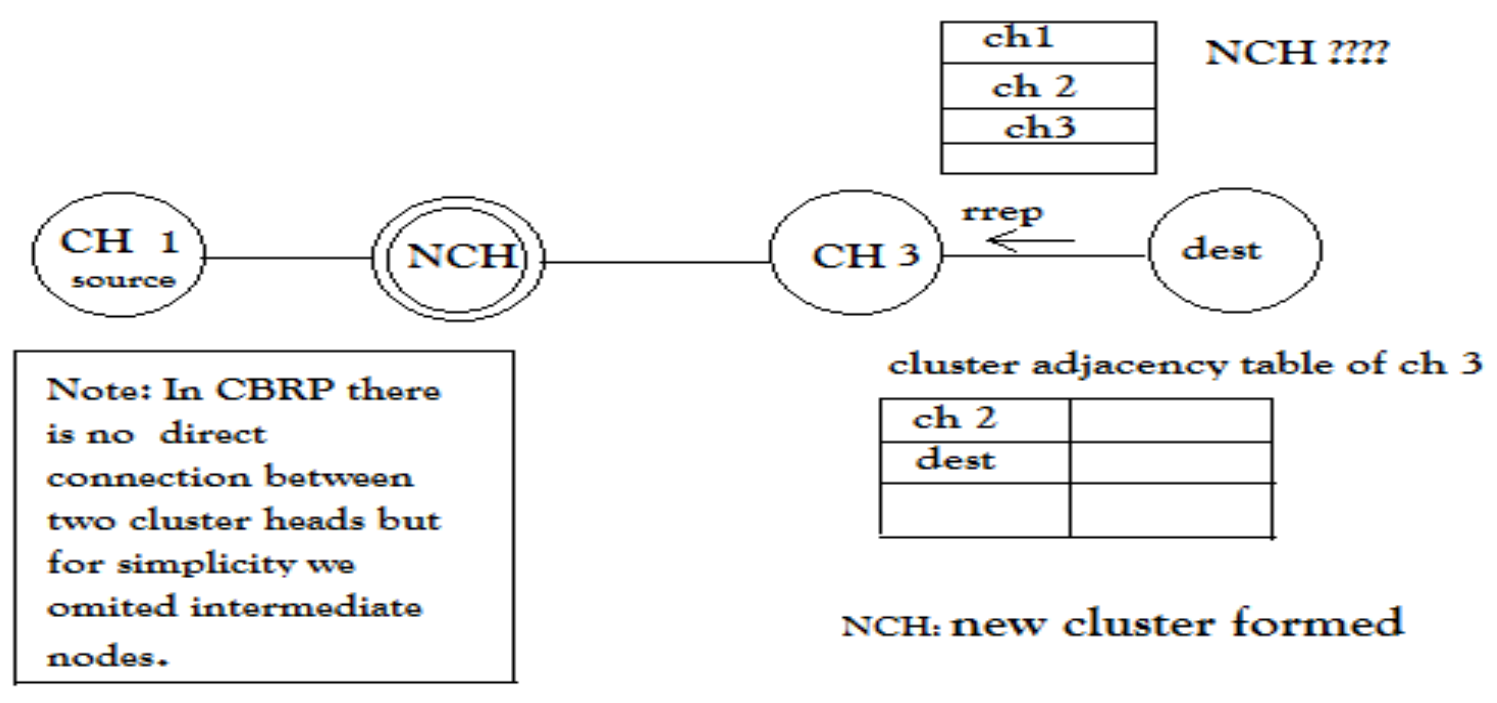

Figure 1. Flaw of CBRP

\subsection{Proposed Solution}

We have proposed solution to CBRP drawback we found. We have proposed to store adjacent cluster information up to depth of 3 .

\subsubsection{Cluster Adjacency}

Table 2. Cluster Adjacency Table

\begin{tabular}{|c|c|}
\hline Adjacent Cluster ID & Gateway \\
\hline & \\
\hline & \\
\hline
\end{tabular}

\subsubsection{Why next 3 adjacent cluster head??}

As we know cluster radius is 1 . So diameter of cluster will be 2 . Whenever there is change in network topology ,i.e if cluster head move or goes off, maximum new clusters can be formed are 2. RREQ packet carries intermediate cluster information. Based on that information RREP, packet constructs path. Suppose RREP packet on its way and certain $\mathrm{CH}$ on its route moves. Maximum new cluster can be formed are 2. So whenever intermediate cluster found that, next cluster address is not present in its adjacency table,it concludes that ,it is old cluster and new clusters are formed. So at this situation looking at third last cluster address ,node forwards packet to corresponding gateway. Path will be constructed according to new clusters formed. So there is will be no discarding of packets at this time. Thus process of retransmission of RREQ will not be happen. Thus keeping record of next 3 clusters solves above problem we found . Only tables of cluster adjacency will be affected during control 
message of HELLO. Less control message overflow will be there. Also process of broadcasting RREQ will be enhanced.

\section{CONCLUSION AND FUTURE WORK}

In this paper we have studied various routing protocols in MANET. Also we have found design flaw in cluster based routing protocol. We have proposed a solution to problem we found in CBRP. Theoretically proposed concept sounds beneficial. However testing of proposed solution with network simulator has not been undertaken and this lies as a future work.

\section{REFERENCES}

[1] P. Michiardi and R. Molva,, "CORE: A Collaborative Reputation Mechanism to Enforce Node Cooperation in Mobile Ad Hoc Networks," IFIP-Communication and Multimedia Security Conf. 2002 .

[2] Mobile Ad hoc Networks: Challenges and Future, Kavita Taneja, B. Patel2, National Conference on Challenges \& Opportunities in Information Technology (COIT-2007) RIMT-IET, Mandi Gobindgarh. March 23, 2007.

[3] MANET: Vulnerabilities, Challenges, Attacks, Application,Priyanka Goyal,Vinti Parmar, International Journal of Computational Engineering \& Management, Vol. 11, January 2011

[4] A Survey of Secure Mobile Ad Hoc Routing Protocols, Loay Abusalah, Ashfaq Khokhar, and Mohsen Guizani IEEE COMMUNICATIONS SURVEYS \& TUTORIALS, VOL. 10, NO. 4, FOURTH QUARTER 2008 .

[5] Georgios Kioumourtzis, "Simulation and Evaluation of Routing Protocols for Mobile Ad Hoc Networks", Thesis, Master of Science in Systems Engineering and Master of Science in Computer Science, Naval Postgraduate School, Monterey, California, 2005.

[6] C. E. Perkins and P. Bhagwat, "Highly dynamic destinationsequenced distance vector routing (DSDV) for mobile computers", Proceedings of ACM SIGCOMM 94, pp. 34-244, 1994.

[7] D. B. Johnson, D. A. Maltz, Y.C. Hu, "The Dynamic Source Routing Protocol for Mobile Ad Hoc Networks (DSR)", IETF Internet Draft, 2003.

[8] A. Kush and S. Taneja, "A Survey of Routing Protocols in Mobile Adhoc Networks", International Journal of Innovation, Management and Technology, Vol. 1, No. 3, pp 279-285, 2010.

[9] Performance Evaluation of ZRP over AODV and DSR in Mobile Adhoc Networks Using Qualnet, European Journal of Scientific Research, SreeRangaRaju , Jitendranath Mungara,2010

[10] Comparative Analysis of CBRP, DSR, AODV Routing Protocol in MANET,Mukesh Kumar, Rahul Rishi ,International Journal on Computer Science and Engineering 2010.

[11] Internet draft "cluster based routing protocol" http://tools.ietf.org/html/draft-ietf-manet-cbrp-spec-01, Mingliang Jiang Li, Y.C. Tay, National University of Singapore, 14 August 1999

Authors:

Prasad R. Patil is pursuing Master of Engineering in Computer Engineering from Vidyalankar Institute of Technology, Mumbai, India. He has completed his Bachelor of Engineering from A. C. Patil College of Engineering Navi Mumbai

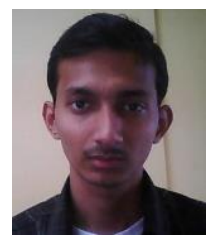

Rinku Shah is working in Computer Engineering department of Vidyalankar Institute of Technology, Mumbai, India.

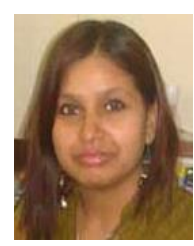

